\title{
Research on the Quality Evaluation of SPOC-Based Blended Learning in Higher Vocational Colleges
}

\author{
Wuxue Jiang ${ }^{1, ~ a}$, Guangzai Ye ${ }^{1, b}$, Bin Xie ${ }^{2, d}$, Cao Chai ${ }^{2, c}$ \\ ${ }^{1}$ Department of Computer Engineering, Dongguan Polytechnic, Dongguan 523808, China \\ ${ }^{2}$ Division of teaching affairs, Dongguan Polytechnic, Dongguan 523808, China \\ ajiangwx@dgpt.edu.cn, bYegz@dgpt.edu.cn, ‘401174996@qq.com, d871403792@qq.com
}

\begin{abstract}
Along with the development of network technology, the concept of "Internet + education" has gradually been valued by the society; the SPOC-based blended teaching fully reflects this feature. The vocational college as research background, this paper explores the evaluation status quo of SPOC-based blended teaching quality, and proposes a series of solutions in combination with the problems in the existing evaluation system.
\end{abstract}

Keywords: vocational colleges; higher vocational education; SPOC teaching; teaching evaluation.

\section{Characteristics of SPOC-based Blended Teaching}

(1) Lay equal stress on self-study and teachers' guidance

SPOC blended teaching is a teaching mode that combines traditional classroom teaching with small-scale restrictive online courses, it is an organic integration of online teaching and offline teaching. In the SPOC-based blended teaching, through online platform, teachers give priority to assigning relevant learning objectives to students, and provide online teaching courses for students, through self-test question bank, homework assignment and submission, course testing, online discussion and answer areas, etc., and help students learn autonomously. Afterwards, based on the students' online academic feedback, the teacher guides the students in the classroom teaching, solving the learning problems as the main way to help students improve their self-study results, and then achieve the teaching goals.

(2) Preserve the central position of classroom teaching

Although SPOC-based blended teaching is a model that combines online teaching with offline teaching, the proportion of online and offline teaching is not completely balanced in practice. In the current teaching application, position of SPOC in blended teaching is still relatively weaker than classroom teaching. In the teaching process, SPOC teaching mainly plays the role of driving and inspiring, and it is the channel to guide students to carry out in-depth learning. Therefore, the SPOC-based blended teaching retains the central position of classroom teaching; which is not a subversion of traditional classroom teaching, but is an extension and optimization of it, and it is a new classroom teaching mechanism integrating online teaching resources.

(3) Students' demands as teaching orientation

In SPOC-based blended instruction, students' demands have been raised to unprecedented height. The biggest difference between SPOC-based blended teaching and traditional teaching is that it uses online resources to complete the transformation from "teacher main body" to "student main body". The teaching process is no longer dominated by the teachers' thinking, but is dominated by students' demands. In the whole SPOC-based blended teaching, the center of teaching is not "what the teachers need to teach", but rather "what the students need to learn." The teacher only undertakes the functions of problem solving, knowledge perfection and frame design, and the real course contents need teachers to decide according to the problems exposed in the student's self-exploration process, namely the design and execution of the teaching plan must focus on the students' demands, rather than focus on teachers' teaching experience or subjective intentions.

(4) Inversion of teaching process

The inversion of teaching process is the most intuitive feature of SPOC-based blended teaching. In the traditional teaching mode, the input-oriented teaching concept is adopted, namely the teachers design syllabus according to individual teaching experience and textbook content - the teachers 
explain the relevant knowledge points in the classroom - the students carry out the exercise practices - the students discover the learning problems - the teacher provides questions explanation. In the SPOC-based blended teaching, the "output-oriented" teaching concept is adopted. The teaching mode of flipped classroom is used to achieve inversion process of students' self-study-discover selfstudy problems - teachers provide guidance - resolve the learning problems. The student's learning comprehension is advanced from the "end of teaching" to the "front end of teaching."

\section{Status Quo of Quality Evaluation of SPOC-based Blended Teaching}

\section{(1) Multi-angle evaluation}

At present, the quality evaluation system of SPOC-based blended teaching mainly comes from the traditional teaching evaluation index, and on this basis, the characteristics of SPOC mode are appropriately integrated, and evaluation indexes of some online resources are added. The quality evaluation of SPOC-based blended teaching has obvious "multi-angle" characteristics. Generally speaking, the quality evaluation system SPOC-based blended teaching includes five aspects: "teaching team, teaching resources, teaching effect, teaching design and teaching support". The process evaluation of teaching and the evaluation of teaching results are emphasized. The multi-angle quality evaluation system makes it better reflect the characteristics of SPOC teaching and the value of classroom teaching.

(2) Multi-level evaluation

In the SPOC-based blended teaching, the evaluation system of teaching quality adopts a more classic multi-level evaluation way. Generally speaking, three-level evaluation mechanism is mainly adopted. The first level indicator is the system level, which is the split of the whole teaching mode, namely the indicators are set according to the structure of "SPOC teaching+ classroom teaching". The second level indicator is the domain level, which is the division of different teaching links or different components, such as teacher team, teaching resources, teaching tools. The third level indicator is the data layer, which is the evaluation of specific teaching data, for example, the secondary indicator "teaching resources" can be divided into three levels of indicators, such as "number of question bank, number of tests, and number of videos". The multi-level evaluation system more precisely reflects the characteristics of SPOC-based blended teaching,

(3) Quantitative evaluation as the principal thing

At present, the quality evaluation of blended teaching based on SPOC mainly adopts the method of quantitative evaluation. For example, the numbers of specific question banks, the average score of students, the time of question response, the number of teacher teams, and so on. The quantitative evaluation has the characteristics of "easy storage, intuitive performance and easy statistics". Under normal circumstances, the quality evaluation data of SPOC-based blended teaching comes from the teacher or authoritative exam statistics system, it emphasizes the objectivity of teaching quality, it avoids the influence of human subjectivity to a certain extent, and it can help teachers to analyze students' growth from a more scientific and objective angle.

\section{SPOC-based Blended Teaching in Vocational Colleges}

(1) Characteristics of SPOC-based blended teaching in vocational colleges

In vocational colleges, the SPOC-based blended teaching needs more emphasis on students' learning ability. Especially in self-exploration learning link, due to the weak basic ability of students in vocational colleges and the insufficient self-study ability, SPOC teaching needs to reduce the proportion of self-exploration appropriately and strengthen the guidance of teachers. In the teaching proportion, vocational colleges pay more attention to the cultivation of practical skills, so more theoretical learning links can be integrated into SPOC teaching links, while classroom teaching needs to emphasize the combination of practice and theory. 
(2) Implementation of SPOC-based blended teaching in vocational colleges

Due to the limitations of teaching resources, teaching conditions and students' ability, the implementation of SPOC-based blended teaching in vocational colleges is not ideal. Although some vocational colleges have established SPOC-based blended teaching mechanism, teachers and students pay less attention to this kind of teaching mode in actual teaching. And due to lack of systematic teaching management, the SPOC-based blended teaching becomes a mere formality. On the one hand, teachers can't follow SPOC-based blended teaching better in teaching design; on the other hand, students' learning initiative for SPOC is poor, some students do not even have the ability to complete self-study goals in the SPOC link.

\section{Problems of SPOC-based Blended Teaching Quality Evaluation}

(1) Lack attention for adaptability of students' learning condition

As far as vocational colleges are concerned, the special nature of students makes all teaching work try to avoid the problem of "idealization". The characteristics of "poor learning enthusiasm, weak learning ability and little basic knowledge" and so on, which make the education work of vocational colleges often encounter the problem of "slow progress and more difficulties". The reason why SPOCbased blended teaching is difficult to implement in vocational colleges is precisely because the idealized SPOC-based blended teaching cannot adapt to the true learning situation of vocational students. The quality evaluation system of SPOC-based blended teaching blindly emphasizes the richness of teaching resources and the professionalism of the teaching staff, but it cannot pay reasonable attention to the actual needs of students. Even if the students' learning results are slightly reflected in the teaching results, the differences between the teaching design and students' actual situation cannot be deeply considered.

(2) Lack attention for students' growth

In the evaluation system of SPOC blended teaching quality of vocational colleges, although the students' academic performance, participation frequency and interactive condition have been evaluated in detail, this evaluation is only based on the "results" level. That is to say, all the teaching quality evaluations belong to "static evaluation" and lack attention of students' growth. The knowledge "increment" that students achieve through teaching cannot be fully reflected in the evaluation system. In the actual SPOC-based blended teaching, the teaching with poor evaluation results is often the problem of teaching quality, but because the difficulty of the course content is high, which ultimately leads to the inaccuracy of teaching quality evaluation.

(3) Lack attention for professional characteristics

Through the arrangement and analysis of existing SPOC-based blended teaching quality evaluation system, it is found that the SPOC-based blended teaching quality evaluation system has obvious similarities in the vocational colleges. The professional teaching quality evaluation systems in most colleges are often applied to any major. However, in actual teaching, professional differences often indicate sharp differences in teaching processes, teaching modes and teaching objectives. This means that the SPOC-based blended teaching quality evaluation system cannot produce reasonable guidance value for professional features, which cause the evaluation to become a mere formality.

\section{Innovative Methods of SPOC-based Blended Teaching Quality Evaluation}

(1) Increase the dynamic evaluation mechanism

The dynamic evaluation mechanism is the evaluation of various "increment". Compared with the traditional SPOC-based blended teaching quality evaluation mechanism, it more emphasizes "before and after comparison of learning outcomes". The dynamic evaluation mechanism reflects the progress level in learning; and to a certain extent, it avoids the problem of inaccurate evaluation due to the differences in course content. The dynamic evaluation mechanism cannot be completed by simple index setting, instead, it is necessary to control the learning process and make use of the improvement of evaluation process to achieve dynamic comparison. The specific flows are: pre-learning ability 
assessment--SPOC learning condition assessment -- learning response condition-- post-learning exercises completion rate.

Pre-learning ability assessment: before the SPOC-based blended teaching, it records the students' knowledge before starting the learning by using test questions evaluation, teacher questions, etc.

SPOC learning condition assessment: after SPOC learning, evaluation of students' mastery condition of professional knowledge, it can be completed by using the same test questions as the prelearning ability assessment.

Learning response condition: it is students' problem response condition and communication frequency in the classroom teaching and the SPOC online interactive link. It reflects the students' initiative to participate in teaching, the higher the initiative, the higher the teaching quality.

Post-learning exercises completion rate: it is students' professional ability after completing the whole SPOC-based blended teaching, it can also be completed by using the same test questions as the pre-learning ability assessment.

Through three result evaluations, we can grasp students' result "increment" in the whole process of SPOC-based blended teaching, and the final evaluation index of learning effect should be based on the increment.

(2) Increase the subjective evaluation mechanism based on students' feedback

In the traditional SPOC-based blended teaching quality evaluation system, most of the evaluation indicators are based on objective data, but in actual teaching, objective data is susceptible to "students' emotions, course difficulty, teachers' status" and many other "uncontrollable factors". These influences are often difficult to reflect through an indicator set in advance. Moreover, in the quantitative teaching quality evaluation, students' real needs and ideas cannot be reflected, which is contrary to "students-oriented" of SPOC-based blended teaching. Therefore, in order to improve the evaluation system of SPOC-based blended teaching quality, the subjective evaluation mechanism based on students' feedback should be appropriately increased.

First, attach importance to students' opinions and increase correction link of evaluation results. On the basis of the quantitative teaching quality evaluation system, students' feedback research is added; students' experiences and opinions in the whole SPOC-based blended teaching process are collected. The existing quantitative evaluation results are corrected in combination with students' feedback information. For example, in the "evaluation of the number of question banks", students' feedback is manifested "the difficulty of the course is high, and most of the questions are not be done", it means that the number of question banks is too large and there is no guidance for the title choice. Therefore, the higher the number of question banks, the lower the teaching quality. Second, pay close attention to special situations and assess the effectiveness of the evaluation results. Through the statistical analysis of the students' feedback information, we find the special situation in the process of SPOCbased blended teaching, and eliminate the interference of exceptional circumstances on the teaching quality evaluation.

(3) Increase evaluation modules with professional characteristics

In allusion to the professional characteristics of vocational colleges and school-running characteristics of colleges, on the basis of the intrinsic SPOC-based blended teaching quality evaluation system, the professional evaluation module is added. The contents of professional courses are combined and the evaluation contents are enriched. For example, in the mechanical automation major, the evaluation of professional practical ability should be increased. In the evaluation of English major, the ability evaluation of oral English and writing should be increased. Moreover, in the setting of the evaluation system, teachers of different majors should improve the quality evaluation system formulated by the colleges, and form a "two-stage" teaching quality evaluation system construction mechanism.

\section{Summary}

The quality evaluation system of SPOC-based blended teaching in vocational colleges should be the teaching quality evaluation system that integrates the whole process of "pedagogy", the school- 
running characteristics and professional characteristics of vocational colleges are combined, and the application of "students-oriented" concept is strengthened, practical evaluation research is conducted. The attention of students' learning condition and learning increment are increased, the attention of vocational colleges' characteristics and professional characteristics is added, and furthermore, it provides elaborate and scientific guidance for the refining of blended teaching evaluation indicators and the construction of evaluation index system.

\section{Acknowledgements}

This work was financially supported by the Guangdong education science 13th five-year plan project (No.2018GXJK293,2018GXJK394), and support by the Teaching achievement cultivation project of Dongguan Polytechnic (CGPY201801, CGPY201802, CGPY201803), and support by Guangdong teaching reform research and practice project (GDJG2019003, GDJG2019004).

\section{References}

[1]. Wang Yang, Wang Yixi, Stein David, et al. Examining Chinese beginning online instructors' competencies in teaching online based on the Activity theory. JOURNAL OF COMPUTERS IN EDUCATION. Vol. 6(2019), No. 3, p. 363-384.

[2]. Reynolds-Tylus Tobias, Lukacena Kaylee M., Quick Brian L. An application of the theory of normative social behavior to bystander intervention for sexual assault. JOURNAL OF AMERICAN COLLEGE HEALTH. Vol. 67(2019), No. 6, p. 551-559.

[3]. Liu, Jin; Guo, Xiuyan; Gao, Ruiqin; et al. Students' learning outcomes and peer rating accuracy in compulsory and voluntary online peer assessment. ASSESSMENT \& EVALUATION IN HIGHER EDUCATION. Vol. 44(2019), No.6. p. 835-847.

[4]. Jiang Wuxue, Chai Pei, Chen Yuqiang, et al. University-enterprise Cooperation Practical Teaching Evaluation Model for polytechnic based on AHP and Fuzzy. International Conference on Computational Science and Engineering (ICCSE). Shandong, JULY 20-21, 2015, p. 282-285.

[5]. Lindert Jutta, Wehrwein Annette, Klemperer David, et al. Public Health Education in HealthRelated Study Programs in Germany: Perspectives from Course Coordinators. GESUNDHEITSWESEN. Vol. 81(2019), No. 8-9, p. 599-605.

[6]. Szarecka Agnieszka, Dobson Christopher. Protein Structure Analysis: Introducing Students to Rational Drug Design. AMERICAN BIOLOGY TEACHER. Vol. 81(2019), No. 6, p. 423-429.

[7]. Jiang Wuxue, Bao Jingjing, Gao Libin, et al. Situational Reconstruction of C Programming Technology based on the Systematic Work Process for polytechnic. 6th International Conference on Applied Science, Engineering and Technology (ICASET). Qingdao, MAY 29-30, 2016, p. 397-402. 